\title{
Afghan Undergraduate Students' Perceptions towards Effective Teaching
}

\section{Faridullah Farid}

Pashto Department, Faculty of Languages and Literature, Shaikh Zayed University, Khost,

Afghanistan

\section{Mirza Khan Nikzoy}

Pashto Department, Faculty of Languages and Literature, Shaikh Zayed University, Khost, Afghanistan

\section{Wali Khan Monib*}

English Department, Faculty of Languages and Literature, Shaikh Zayed University, Khost, Afghanistan.

*E-mail: walikhan.af@gamil.com

\begin{abstract}
:
The aim of this article is to explore Afghan undergraduate students' perceptions towards effective teaching at a public university. Data were collected based on a Likert scale questionnaire containing 32 items from 47 respondents. The results show that although the ability of teachers to teach and help students are vital, their attitudes towards students are considered crucial for judging their effectiveness. Most of the students perceived that a teacher who has excellent knowledge of the subject, well prepared, value students' opinions and contribution, start sessions on time, provide both group activities and assessment briefs considered very effective. The article concludes by suggesting that notions of effectiveness are predicated less on university teachers having high academic expectations and more on the provision of a supportive environment in which teachers scaffold learning effectively and promote effective interaction with their students.
\end{abstract} Keywords: Afghan Undergraduate Students, Perception, Effective Teaching 


\section{Introduction}

In the past, traditional teaching and learning methods were used at the universities of Afghanistan. Lecturers were relying on frontal teaching or lecturing where students would passively listen to them in the classroom. For instance, lecturers were just presenting what they have already prepared related to the topic and students would take notes without proper interaction with the lecturers. However, some innovations and changes began in the early $21^{\text {st }}$ century because many lecturers acquainted with technology, especially the use of computers, in the educational system. Although different teaching methods were used, the dominant one was teacher-centered. The lecture-based method is still in use with minor adaptation by infusing technology. If we want to create an active learning environment, it is important to use student-centered methods. Facilitating students learning, we should give more chances to students to participate in lessons. Those instructional methods which are already proved to be effective in teaching and learning such as student-centered have to be applied. Several educational studies found an important relationship between student attitudes to the evaluation of the effectiveness of instruction and the success of a system for teaching assessment. However, to the best of the researchers' knowledge, less research has been conducted in the context of Afghanistan investigating effective teaching from undergraduate students' perspectives. Hence, the aim of this study is to investigate the perceptions of Afghan undergraduate students towards effective teaching.

\subsection{Research Questions}

a) What are the perceptions of Afghan undergraduate students towards effective teaching?

b) What are the qualities of teachers that students perceive to promote their learning?

\section{Literature Review}

Generally speaking, research regarding teaching have focused on different aspects and themes which include method and technique (e.g., Galbraith, 2004; Svinicki \& McKeachie, 2010; Davis, 2009), supporting and caring for students' learning (e.g., Kasworm, 2008), the meaning of learning for students (e.g., Weimer, 2002), human emotion and learning relationships (e.g., Kasworm, 2008). According to Hyland (2010), learning involves "the development of knowledge, values, emotions, understanding, reason, skill, experience and insight” (p.525), involving both knowledge acquisition and guidance of students on how learning can be appropriate to their lives, 
How it applies to their roles and how it is relevant to their life experiences (Hooks, 1994; Kanuka, 2010; Kasworm, 2008). Vella (2002) articulated the importance of creating a relationship between teachers and learners that involves respect, safety, open communication, affirmation, listening, and humility. Specifically, classroom safety involves trust in the knowledge and competency of the instructor; trust in the design of the course including the sequencing of activities, feasibility and relevance of course objectives, and maintenance of a non-judgmental environment. In addition, Schoeberlein (2009) advocated for the use of silence, mindful listening, humility, and presence. Teachers can nourish students' inner lives and encourage them to create their learning rather than simply filling them with the teacher's knowledge. That is why "Effective teaching" is indeed hard to define. It is often portrayed in literature and academic settings that effective teaching practices are clearly important for raising student achievement, and characteristics of the same are rather mysterious. The reality is that there is no single factor, nor consensus in the literature, about what is, or what are the components of effective teaching (Hande, 2014). Rather than anyone teacher behavior is strongly related to achievement, effective teaching is not being able to do a small number of 'big' things right but is rather doing a large number of 'little' things well (Reynolds, 2011). Generally, researchers identify three main types of teacher knowledge: teachers' subject knowledge (what they know about the subject they are teaching), teachers' pedagogical knowledge (what they know about effective teaching), and teachers' pedagogical subject knowledge (what they know about the effective teaching of their specific subject) (Reynolds, 2011). Given the contingent and constructive nature of what counts as effective teaching, the ways in which effectiveness is measured will have a direct impact on the potential of any reform policy to positively influence the overall effectiveness of a teaching force and therefore the achievement of its students. Therefore, it is suggested to encourage local adaptations of global policies for encouraging and measuring effective teaching (Gabriel \& Richard, 2015).

On the other hand, though schools cannot and should not take responsibility for the influence of student health, housing, poverty, and family status (Ravitch, 2010), there are countless examples of effective teachers leading students to overcome such odds in terms of their academic achievement. Therefore, it is written from the perspective that teacher effectiveness is a key lever in the improvement of educational opportunities for all students, especially those at socioeconomic risk. However, there are no static or universal definitions for effective teaching as stated earlier. 
What counts as effective is in part determined by the tools selected to measure it, and in part by local values about the goals of education (Anderson, 1991). In the case of teaching and learning, how we choose to represent teaching within definitions of effectiveness and evaluation criteria alters how teaching is interpreted and understood. As Anderson (1991) cautions, teachers' effectiveness is predicated on their ability to consistently reach the implicit and explicit goals set both by them and for them by others. It is, therefore, possible that a teacher is effective in terms of some, but not all of the metrics they are held accountable for. This method also assumes that there are universals of effective teachers that can be applied and made visible across settings. Hence, this study aims to investigate the perceptions of Afghan undergraduate students towards effective teaching.

\section{Methodology}

\subsection{Research Design}

The overall strategy used to carry out research that outlines a clear and logical plan to handle established research question(s) through data collection, interpretation, analysis, and discussion is referred to as research design . The current research study is based on a quantitative approach whereby a survey design is used to investigate the perceptions of Afghan undergraduate students on the proposed questions related to effective teaching. Survey research designs are techniques in which a researcher distributes a questionnaire to the entire population or a sample of participants to describe the "behaviors, opinions, attitudes, beliefs, characteristics, perceptions and their experiences" about current issues (e.g., Creswell, 2012; Neuman, 2014). According to Creswell (2012), an issue is found by the researcher when performing quantitative analysis "based on field patterns or the need to clarify why anything happens." In addition, working with and gathering organized and numerical data, or data that can be numerically interpreted is a part of quantitative analysis methods (Tracy, 2013). Gathering factual information, surveys are useful and relatively easy to access students and teachers (Cohen, Manion \& Morrison, 2013). Other reasons for its prevalence are "practicality and cost-effectiveness" (Mathers, Fox \& Hunn, 2007).

\subsection{Participants}

The research involved undergraduate students of the Languages and Literature Faculty from Shaikh Zayed University. During the data collection process, the researchers sent a consent form to the participants along with the questionnaire. They were selected based on stratified sampling. Stratified sampling is a sampling method that divides a population into sub-groups called strata 
based on similar characteristics shared by their members (Sharma, 2017). Hence, the population was divided into strata based on the supplementary data. Secondly, the sampling frame was divided by the strata and then the respondents were drawn through random sampling from each stratum. Both active and graduate students' perspectives were asked on effective teaching. In this regard, a total of 47 students were able to complete and return the questionnaires.

\subsection{Research Instrument}

To collect data for this research study, a survey instrument was adopted on effective teaching from Allan, Clarke, and Jopling (2009). Typically, teaching effectiveness is measured through some forms of student questionnaires that have been specifically designed to measure observed teaching styles or behaviors (Wright \& O'Neil, 1992). The instrument is concerned with the perceptions of students regarding effective teaching. The instrument measured on a five-point Likert scale was given to the respondents where they could demonstrate strong disagreement (1), disagreement (2), neutrality (3), agreement (4), or strong agreement (5) in response to each of the statements.

\subsection{Background of the Respondents}

Information required for this part is gender and academic qualifications of the respondents including freshman, sophomore, junior or senior; degree pursuing. Table 1. Since the chosen public university where the survey was conducted does not have any master or Ph.D. programs in the related field, only bachelor students were involved. The numbers of males were $45(95.7 \%)$ making a large proportion while females made $2(4.3 \%)$ of teachers as participants. There were $14(29.8 \%)$ freshman, 3 (6.4\%) sophomore, 15 (31.9\%) junior and 11(23.4\%) senior. Of these, the majority 34 (72.34) were 25-30 years old, 13 (27.66\%) were 31-35 years old and no one (0\%) were more than 35 years old.

Table 1. 1 Demography of the respondents

\begin{tabular}{|l|c|l|c|c|}
\hline \multicolumn{2}{|c|}{ Demographic Variables } & Frequency & Percentage \% \\
\hline Total & Year & Senior & $\mathbf{4 7}$ & $\mathbf{1 0 0} \%$ \\
\hline Respondents & Junior & 11 & $23.4 \%$ \\
& & Sophomore & 15 & $31.9 \%$ \\
& & Freshman & 7 & $14.89 \%$ \\
& & & 14 & $29.8 \%$ \\
\hline
\end{tabular}


Academic Journal of Research and Scientific Publishing | Vol 3 | Issue 30

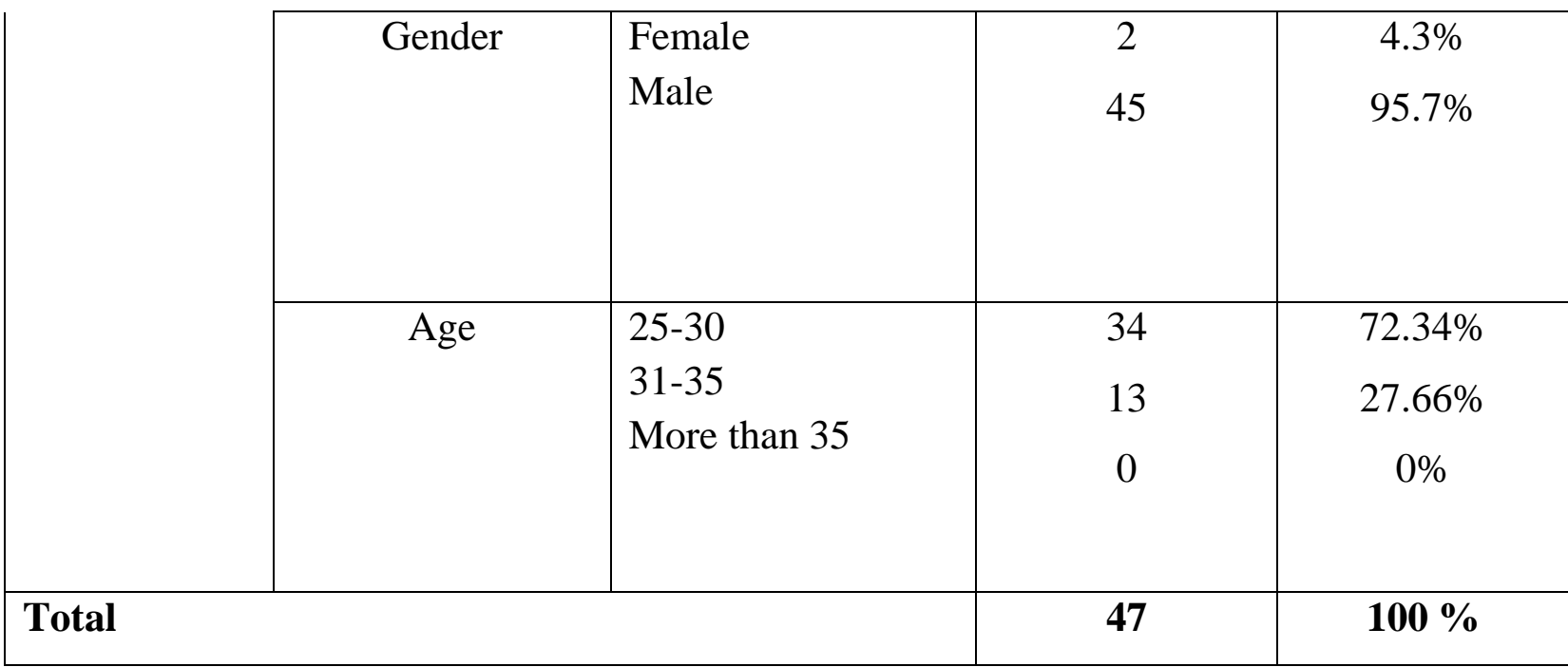

The second part of the questionnaire comprises thirty-two (32) items regarding effective teachers where each item indicates a contribution to teachers' effective teaching. Reliability refers to dependability or consistency of answers from one set of items to another occurring under very similar conditions (Neuman, 2014; Cohen, Manion \& Morrison, 2013; Fraenkel, Wallen \& Hyun, 1993) was done as part of another study. The internal consistency of the questionnaire was rechecked in the current study for the new sample of the participants. Cronbach's Alpha which is one of the three best-known ways (test-retest, equivalent-form, and internal-consistency methods) to test reliability coefficient was performed (Fraenkel, Wallen \& Hyun, 1993).

Table 1. 2 Reliability test of the instrument

\begin{tabular}{|l|c|c|}
\hline Cronbach's Alpha & $\begin{array}{l}\text { Cronbach's Alpha based on } \\
\text { standardized items }\end{array}$ & Number of items \\
\hline 0.844 & 0.970 & 32 \\
\hline
\end{tabular}

A reliability analysis based on Cronbach's Alpha coefficient yielded acceptable results across all 32 items of the questionnaire, as shown in Table 1.2. The index for all items combined had alpha= 0.970. This ensures that all of the items are internally reliable, and the instrument chosen for the current study is suitable.

\subsection{Data Analysis}

To address both research questions in the current study, the researcher solely relied on the quantitative data collection method. 
The information is gathered using a closed-ended questionnaire that was provided to Afghan undergraduate students in order to determine effective teaching. The data is analyzed employing SPSS version 25, using descriptive statistics. According to Thompson (2009), "descriptive statistics are numbers that summarize the data to describe what occurred in the sample."

\section{Result}

A total of 47 sets of valid questionnaires were collected from the participants through an online survey. In Section 1 of the Questionnaire, background information and the frequencies of the participants are counted. The second part is frequency related to effective teaching which is measured on a 5-point Liker scale. The scales range from strongly disagree (1), disagree (2), neutral (3), agree (4), or strongly agree (5) in response to each of the statements. Table 1.3 shows the percentage related to each item of effective teaching. The overall findings indicated students' agreement concerning effective teaching was with an average of $75.18 \%$ with minor disagreement $12.17 \%$ and $12.62 \%$ neutral.

Table 1.3 Effective Teaching

\begin{tabular}{|l|l|l|l|l|l|l|}
\hline $\mathbf{N}$ & Statements & $\mathbf{A}$ & $\mathbf{S A}$ & $\mathbf{N}$ & $\mathbf{D}$ & SD \\
\hline 1 & & 29.8 & 68.1 & 2.1 & 0 & 0 \\
\hline 2 & $\begin{array}{l}\text { Demonstrate the research they take in their } \\
\text { subject area. }\end{array}$ & 59.6 & 14.9 & 14.9 & 2.1 & 8.5 \\
\hline 3 & $\begin{array}{l}\text { Relate their research directly to module } \\
\text { sessions. }\end{array}$ & 55.3 & 17.0 & 14.9 & 6.4 & 6.4 \\
\hline 4 & Relate theory to work-based practices. & 53.2 & 23.4 & 12.8 & 2.1 & 8.5 \\
\hline 5 & Encourage discussion. & 44.7 & 29.8 & 8.5 & 8.5 & 8.5 \\
\hline 6 & $\begin{array}{l}\text { Enable students to understand the content of } \\
\text { each session. }\end{array}$ & 61.7 & 14.9 & 4.3 & 12.8 & 6.4 \\
\hline 7 & $\begin{array}{l}\text { Create a safe climate for all students to } \\
\text { participate in the discussion. }\end{array}$ & 51.1 & 23.4 & 12.8 & 6.4 & 6.4 \\
\hline 8 & $\begin{array}{l}\text { Convey knowledge in a way that is } \\
\text { accessible to students. }\end{array}$ & 55.3 & 23.4 & 10.6 & 2.1 & 8.5 \\
\hline 9 & $\begin{array}{l}\text { Ensure the relevance of information within } \\
\text { sessions. }\end{array}$ & 57.4 & 14.9 & 19.1 & 2.1 & 6.4 \\
\hline
\end{tabular}




\begin{tabular}{|c|c|c|c|c|c|c|}
\hline 10 & $\begin{array}{l}\text { Do not put students on the spot when } \\
\text { questioning. }\end{array}$ & 46.8 & 12.8 & 27.7 & 6.4 & 6.4 \\
\hline 11 & Are patient. & 51.1 & 14.9 & 17 & 12.8 & 4.3 \\
\hline 12 & $\begin{array}{l}\text { Recognize that students learn at different } \\
\text { rates. }\end{array}$ & 48.9 & 21.3 & 10.6 & 12.8 & 6.4 \\
\hline 13 & Are prepared to explain. & 57.4 & 25.5 & 6.4 & 6.4 & 4.3 \\
\hline 14 & Encourage students to ask questions. & 46.8 & 34.0 & 2.1 & 10.6 & 6.4 \\
\hline 15 & Are enthusiastic about learning. & 44.7 & 34.0 & 10.6 & 2.1 & 8.5 \\
\hline 16 & $\begin{array}{l}\text { Explain any new language or concept } \\
\text { clearly. }\end{array}$ & 36.2 & 40.4 & 4.3 & 8.5 & 10.6 \\
\hline 17 & $\begin{array}{l}\text { Acknowledge previous learning/work } \\
\text { experience of students. }\end{array}$ & 57.4 & 19.1 & 10.6 & 4.3 & 8.5 \\
\hline 18 & Are approachable. & 34.0 & 34.0 & 21.3 & 4.3 & 6.4 \\
\hline 19 & Respect students' opinions. & 48.9 & 44.7 & 6.4 & 0 & 0 \\
\hline 20 & Give clear guidance when asked for help. & 57.4 & 17.0 & 25.5 & 0 & 0 \\
\hline 21 & Value students' contribution. & 66.0 & 27.7 & 4.3 & 2.1 & 0 \\
\hline 22 & $\begin{array}{l}\text { Give examples drawn from their own } \\
\text { experiences. }\end{array}$ & 31.9 & 34.0 & 29.8 & 4.3 & 0 \\
\hline 23 & Start sessions on time. & 34.0 & 55.3 & 10.6 & 0 & 0 \\
\hline 24 & Use PowerPoint as prompt only. & 23.4 & 8.5 & 14.9 & 44.7 & 8.5 \\
\hline 25 & $\begin{array}{l}\text { Limit the information given in any one } \\
\text { session. }\end{array}$ & 61.7 & 6.4 & 19.1 & 6.4 & 6.4 \\
\hline 26 & Allow adequate time for discussion. & 55.3 & 14.9 & 8.5 & 14.9 & 6.4 \\
\hline 27 & Give full citation for any references given. & 46.8 & 19.1 & 25.5 & 6.4 & 2.1 \\
\hline 28 & Customise information for their students. & 57.4 & 21.3 & 8.5 & 2.1 & 10.6 \\
\hline 29 & Explain inconsistency clearly. & 51.1 & 17.0 & 19.1 & 4.3 & 8.5 \\
\hline 30 & Provide clear assessment briefs. & 38.3 & 53.2 & 8.5 & 0 & 0 \\
\hline 31 & Include group activities during sessions. & 53.2 & 27.7 & 8.5 & 6.4 & 4.3 \\
\hline 32 & Recap lesson & 66.0 & 10.6 & 4.3 & 12.8 & 6.4 \\
\hline \multicolumn{2}{|c|}{ Total } & 49.46 & 25.72 & 12.62 & 6.72 & 5.45 \\
\hline
\end{tabular}


The results of Table 1.3 indicate that students perceive that a number of teacher qualities and practices contribute to effective instruction. Analysis of the responses to the Likert scale questionnaire shows four responses with the highest proportion of strongly agree and agree. In this regard, item 1 which is to demonstrate excellent knowledge of their subject comes in the first rank in the highest agreement. Ninety-seven-point nine percent of the respondents show their agreement that in effective higher education teaching a teacher should demonstrate excellent knowledge of his or her subject. For item 21, 93.7\% of the students agreed that effective teaching includes valuing students' contributions. This was closely followed by respecting students' opinions $93.6 \%$ and providing clear assessment briefs $91.5 \%$ respectively while none of them disagreed with these items. Starting sessions on time was agreed $89.4 \%$ whilst $10.6 \%$ were of neutral idea and no respondent was of disagreement. Two other items which consisting of prepare to explain $82.9 \%$ and both include group activities during sessions and encourage students to ask questions $80.8 \%$ were preferred to be part of the effective teaching only with $10 \%$ disagreement. The respondents' agreement indicates $78.7 \%$ with three items which are knowledge in a way that is accessible to students and is enthusiastic about learning and customize information for their students with only $10 \%$ of neutral each. Concerning item 4 which relates theory to work-based practices, item 6 enables students to understand the content of each session, item 16 explains any new language or concept clearly and item 33 recap lesson are agreed 76.6\%. Item 18 which is acknowledged previous learning/work experience of students was reported $76.5 \%$, closely followed with a percentage of 74.5 by three items that is item 7 create a safe climate for all students to participate in the discussion, encourage discussion, item 2 demonstrate the research they take in their subject area and item 21 give clear guidance when asked for help 74.4\% while ensuring the relevance of information within sessions $72.3 \%$, and the two others including recognize that students learn at different rates and allow adequate time for discussion are agreed $70.2 \%$. The remaining items were perceived to be agreed less than $70 \%$ where item do not put students on the spot when questioning $59.6 \%$, item 11 that is patient $66 \%$, item 18 is approachable $68 \%$, item 22 give examples drawn from their own experiences 65.9\%, item 25 limit the information given in any one session $68.1 \%$, item 27 give the full citation for any references given $65.9 \%$ and item 29 explain inconsistency clearly $68.1 \%$. 


\section{Discussion}

The findings of the current study indicate that three-fourth of the respondents expressed their agreement concerning effective teaching with a small number of students who stated either neutrality or disagreement. Meaning that a large number of the participants perceive that the stated skills are part of effective teaching. indeed, this facet of effective teaching also features that students believe that effective teaching in higher education requires teachers to demonstrate excellent knowledge of his or her subject, value students' contribution, respect students' opinions and provide clear assessment briefs with minimal disagreement to each of the mentioned items. This broad level agreement of the participants points that effective teaching must include the mentioned characteristics. Starting sessions on time was what emphasized as part of the best teaching practices with more than three-fourth of the respondents. This suggests that students do indeed regard in high esteem those teachers who prioritize their teaching. It may also imply that teachers in higher education are loosely following time management in the context of Afghanistan. Besides, what is of importance is that a large number of the participants agree that effective teaching takes place when teachers prepare to explain and include group activities during sessions and encourage students to ask questions. The high value placed by students on group activities and encouraging discussion in sessions chimes with the consensus of teachers' views on the contribution that varying ways of teaching content, promoting active learning,

and assuring a high level of engagement make to effective learning. This means that students are concerned with their active involvement in the classroom. This finding is consistent with the study of Allan, Clarke, and Jopling who found that a high value placed by students on including group activities and encouraging discussion in sessions chimes with the consensus of teachers' views on the contribution that varying ways of teaching of content, promoting active learning, and assuring a high level of engagement make to effective learning. Lacking preparation to explain and not involving students in group activities can be part of ineffective instruction and learning. The respondents' agreement indicates that the presentation of knowledge has to be in a way that is accessible to students. In fact, inaccessibility to intended knowledge in line with the objectives specified in the related syllabus and curriculum defects the important part which is learning. This is because of the information which students should access first and then prepare to learn. Being enthusiastic about learning is the other characteristic of productive and efficient teaching agreed to a great extent by the students indicating that a strong feeling and excitement about learning is 
required for a more powerful teaching environment. Subsequently, a similar agreement of the respondents in relation to customize information for students signifies those teachers should bring changes in the information to fit the needs or requirements of the students. In addition, the majority of the participants indicated their agreement towards relating theory to work-based practices, enabling students to understand the content of each session, explaining any new language or concept clearly, recapping lessons, and acknowledging previous learning or work experience of students. To teach effectively, teachers are required to consider the named traits seriously. Twothird of respondents were in favor of the notions that creating a safe climate for all students to participate in the discussion, encourage discussion, demonstrating the research they take in their subject area, and giving clear guidance when asked for help should be integrated in effective teaching while closely followed by ensuring the relevance of information within sessions, recognizing that students learn at different rates and allowing adequate time for discussion are agreed.

\section{Conclusion}

It is often portrayed in literature and academic settings that effective teaching practices are clearly important for raising students' achievement, and characteristics of the same are rather mysterious. Hence, the aim of this study was to investigating Afghan undergraduate students' perceptions towards effective teaching.

The findings indicate that students considered a supportive learning environment in which teachers scaffold learning as a requirement of good teaching. This is supported by each of the top-ranked items. The students not only prefer activities that directly contribute to the improvement of learning but also emphasize instructional techniques and teachers' characteristics that help in the fostering relationship between students and teachers. This implies that students consider themselves as active participants in learning, not just mere recipients of knowledge. the present study is a small step in part because of its small size of participants, perception of the Faculty of Languages and Literature learners, and the quantitative data for this study are only based on the self-report questionnaire. But it is hoped that the findings in this study will help future researchers study this issue with more learners in-depth. 


\section{References}

Allan, J., Clarke, K., \& Jopling, M. (2009). Effective Teaching in Higher Education: Perceptions of First-Year Undergraduate Students. International Journal of Teaching and Learning in Higher Education, 21(3), 362-372.

Anderson, L. (1991). Fundamentals of educational planning series: Increasing teacher effectiveness. Paris: UNESCO: International Institute for Educational Planning.

Cohen, L., Manion, L., Morrison, K. (2013). Research Methods in Education. London: Routledge. Creswell, J. W. (2012). Educational research: planning. Conducting, and Evaluating. New York: Pearson Education, Inc.

Davis, B. G. (2009). Tools for teaching (2nd ed.). San Francisco, CA: Jossey-Bass.

Fraenkel, J. R., Wallen, N. E., \& Hyun, H. H. (1993). How to design and evaluate research in education (Vol. 7). New York: McGraw-Hill.

Galbraith, M. (2004). Adult learning methods: A guide for effective instruction (3rd ed.).

Malabar, FL: Krieger.

Hande, H. S., Kamath, S. R., \& D’Souza, J. (2014). Students' perception of effective teaching practices in a medical school. Education in Medicine Journal, 6(3), 63-66.

Hooks, b. (1994). Teaching to transgress: Education as the practice of freedom. New York, NY:

Routledge.

Hyland, T. (2010). Mindfulness, adult learning and therapeutic education: Integrating the cognitive and affective dimensions of learning. International Journal of Lifelong Education, 29, 517-532.

Kanuka, H. (2010). Characteristics of effective and sustainable teacher development programmes for quality teaching in higher education. Higher Education Management and Policy, 22(2), 69-81.

Kasworm, C. E. (2008). Emotional challenges of adult learners in higher education. New Directions for Adult and Continuing Education, 2008(120), 27-34.

Mathers, N., Fox, N., \& Hunn, A. (2007). Surveys and Questionnaires. Trent Focus Group. Neuman, W. L. (2014). Social research methods: Qualitative and quantitative approaches. Boston: Pearson.

Ravitch, D. (2010). The death and life of the great American school system: How testing and choice are undermining education. New York: Basic Books. 
Reynolds, D. M. D. (2011). Effective Teaching Evidence and Practice (third ed.). Los Angeles: SAGE.

Schoeberlein, D. (2009). Mindful teaching and teaching mindfulness: A guide for anyone who teaches anything. Boston, MA: Wisdom.

Sharma, G. (2017). Pros and cons of different sampling techniques. International journal of applied research, 3(7), 749-752.

Svinicki, M., \& McKeachie, W. J. (2010). McKeachie's teaching tips: Strategies, research, and theory for college and university teachers (13th ed.). Belmont, CA: Wadsworth.

Thompson, C. B. (2009). Descriptive data analysis. Air medical journal, 28(2), 56-59.

Tracy, S.J. (2013) Qualitative research methods. Wiley-Black Well, West Sussex.

Vella, J. (2008). On teaching and learning: Putting the principles and practices of dialogue education into action. San Francisco, CA: Jossey-Bass.

Weimer, M. (2002). Learner-centered teaching: Five key changes to practice. San Francisco, CA: Jossey-Bass.

Wright, W., \& O'Neil, M. (1992). Improving summative student ratings of instruction practice.

Journal of Staff, Program, and Organizational Development, 10, 75-85.

Claybaugh, Zach. "Research Guides: Organizing Academic Research Papers: Types of Research Designs". library.sacredheart.edu. Retrieved 2021-9-7.

Copyright (C) 2021 aridullah Farid, Mirza Khan Nikzoy, Wali Khan Monib, AJRSP. This is an open-access article distributed under the terms of the Creative Commons Attribution License (CC BY NC).

Doi: doi.org/10.52132/Ajrsp.e.2021.307 